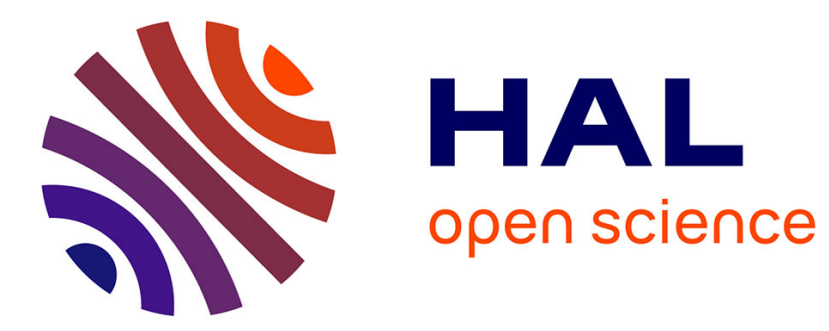

\title{
High Performance Magnetic Head for MiniDisc System
}

T. Roppongi, I. Chiba, T. Minakawa, T. Okamoto, T. Wada, I. Sato

\section{To cite this version:}

T. Roppongi, I. Chiba, T. Minakawa, T. Okamoto, T. Wada, et al.. High Performance Magnetic Head for MiniDisc System. Journal de Physique IV Proceedings, 1997, 07 (C1), pp.C1-151-C1-152. 10.1051/jp4:1997153 . jpa-00255100

\section{HAL Id: jpa-00255100 https://hal.science/jpa-00255100}

Submitted on 1 Jan 1997

HAL is a multi-disciplinary open access archive for the deposit and dissemination of scientific research documents, whether they are published or not. The documents may come from teaching and research institutions in France or abroad, or from public or private research centers.
L'archive ouverte pluridisciplinaire HAL, est destinée au dépôt et à la diffusion de documents scientifiques de niveau recherche, publiés ou non, émanant des établissements d'enseignement et de recherche français ou étrangers, des laboratoires publics ou privés. 


\title{
High Performance Magnetic Head for MiniDisc System
}

\author{
T. Roppongi, I. Chiba, T. Minakawa*, T. Okamoto, T. Wada and I. Sato \\ Advanced Products Development Center, TDK Corporation, 2-15-7 Higashi-Ohwada, Ichikawa-shi, \\ Chiba 272, Japan \\ * Materials Research Center, TDK Corporation, 570-4 Aza-Matsugashita, Minami-hatori, Narita-shi, \\ Chiba 286, Japan
}

\begin{abstract}
A compact and thin magnetic head is indispensable in obtaining a compact MiniDisc (MD) system for both a portable audio device and a computer data storage device. Double speed recording operation is also important. To satisfy the requirements, we have developed a compact and thin magnetic head for MD system by optimizing the core shape with a high magnetic flux efficiency. This head adopts a newly developed low loss $\mathrm{Mn}-\mathrm{Zn}$ ferrite for the head core. The magnetic head enables double speed recording operation from $400 \mathrm{kHz}$ to $1.44 \mathrm{MHz}$ at the disk velocity of $2.8 \mathrm{~m} / \mathrm{s}$, in addition to stable following ability and sliding durability to the disk rotation.
\end{abstract}

\section{Introduction}

MiniDisc (MD) system was introduced in 1992 as a successive device of audio tape. Recently this system has also been used as computer data storage device, known as MD DATA, in addition to audio devices. MD system's requirements for magnetic head are as follows: (1) Compactness, (2) High magnetic flux efficiency of the head core, (3) High frequency recording operation for high speed data transfer, (4) Possession of wide effective magnetic field area for recording operation, (5) High durability for sliding, (6) Following ability to the disk surface with a constant head loading. For item (4), it is also necessary to obtain high assembling tolerances of both the magnetic head and optical head. A high assembling tolerance implies adopting a large scaled E-shaped core which results in a lower magnetic flux efficiency and an increase in both the head temperature and the recording current. This needs to be solved to achieve double speed recording from $400 \mathrm{kHz}$ to $1.44 \mathrm{MHz}$.

This paper describes the design and experimental results of a newly developed compact and thin magnetic head which enables double speed recording operation.

\section{MD System configuration}

MD system utilizes the magneto-optical recording method. This consists of an optical head and a magnetic head located each other on opposite side of a disk. This magnetic head generates the magnetic field, according to the recording signal on a 2.5 inch diameter disk. The magnetic head slides on the disk surface for recording operation. The magnetic elements of the magnetic head are comprised of an E-shaped soft ferrite core and coil wound around a center core element. The new head is shown in Fig.1.

3. Experimental results and Discussion

\subsection{Design of the core shape and core permeability}

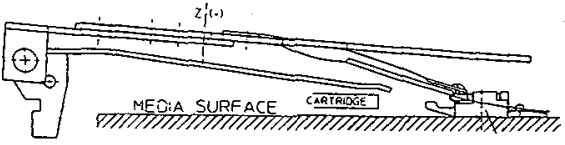

LOAO POSTION

Fig. 1 Construction of the newly developed magnetic head for MiniDisc

Fig. 2 shows the construction of the E-shaped core. Due to the magnetic field simulation by using the two-dimensional finite element method, the effects of the core dimension and the core permeability on the magnetic field are identified. Fig. 3 shows the dependence of the vertical magnetic field and effective magnetic field length on the height difference between the mainpole and the sub-poles. Fig.4 shows the simulated results of the relationship between the core permeability and the magnetic field. Based upon the simulation and experimental results, the compact and thin E-shaped core was designed which generates a magnetic field of more than 1000 , which is sufficient for recording with wide margin. As shown in Fig.5, the newly developed head shows lower inductance than that of a conventional head. Therefore we were able to lower the recording current by $10 \%$, which results in a reduction of the head temperature during recording operation.

\subsection{Core loss of the E-shaped core}

In double speed recording operation, the temperature rise of the magnetic head becomes critical. The temperature increase 
is caused by the joule heat and the core loss. The joule heat is determined by the coil resistance and the recording current. In order to reduce the core loss, we have developed a $\mathrm{Mn}-\mathrm{Zn}$ ferrite with lower core loss for E-shaped core. Fig.6 shows the temperature dependence of the core loss. The newly developed ferrite has a negative temperature coefficient in the operating temperature range, up to $+70^{\circ} \mathrm{C}$. The core loss is lower than $800 \mathrm{~kW} / \mathrm{m}^{3}$ at $80^{\circ} \mathrm{C}$ and $1 \mathrm{MHz}$. Due to the adoption of this ferrite, the temperature rise of the new head is about $20^{\circ} \mathrm{C}$ lower than that of a conventionai one and the temperature rise of a disk surface caused by the contact of the head is less than $5^{\circ} \mathrm{C}$.

\subsection{Characteristics of the magnetic head}

E-shaped core is installed in the slider which is connected to the suspension, which in turn is optimally designed by the simulation so as to perform the stable recording operation. CNR of the reproduced output signal at double speed is more than $46 \mathrm{~dB}$, sufficient for the signal detection. More than twenty million recording operations on a disk were performed without any severe damage to either the head or the disk.

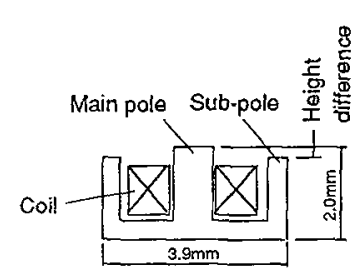

Fig.2 Construction of E-shaped core

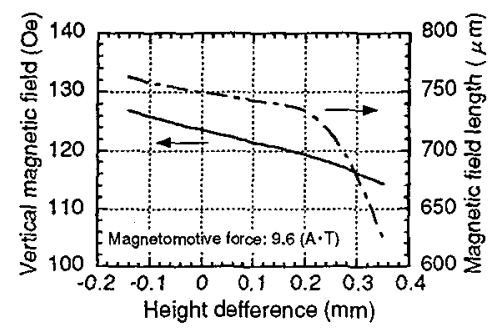

Fig. 3 Shape dependence of the core performances

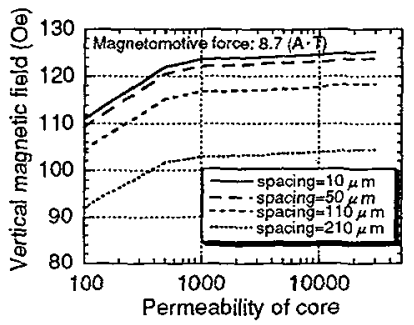

Fig.4 Relationship between the magnetic field and the permeability of core

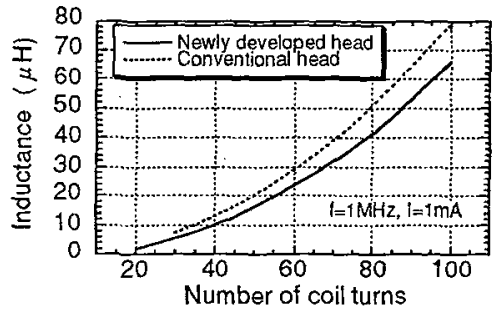

Fig.5 Experimental results of inductance vs. number of coil turns

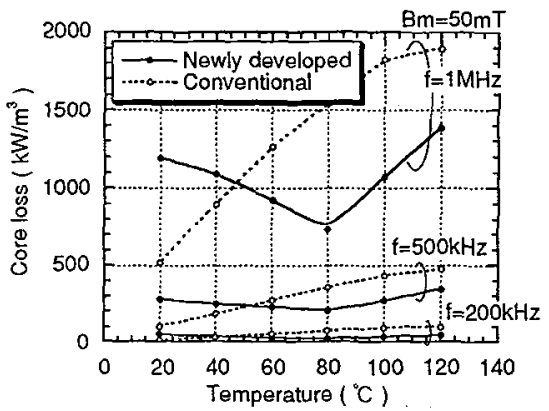

Fig.6 Temperature dependence of the core loss

\section{Conclusions}

Due to the optimized core shape design and the adoption of lower loss $\mathrm{Mn}-\mathrm{Zn}$ ferrite for the core, a thin and efficient magnetic head for MD system was developed. The new magnetic head for MD system has the following characteristics.

(1)Compact and thin construction with $3 \mathrm{~mm}$ thickness at the retract position

(2)Stable recording operation both at conventional and double speed

(3)Stable following ability on a disk due to the optimally designed slider and suspension with a constant loading force

(4)Higher durable recording operation of more than twenty millions passes

\section{Acknowledgments}

We are grateful to M.Kakizaki and T.Ito of Data Storage Components Business Group in TDK, for producing this head.

\section{References}

[1] "MiniDisc System Technical Manual" (1992), SONY Co.

[2] K.Yazawa, JAS Journal (in Japan), Vol.1 (1993), pp. 31.

[3] M.Takeshi, Lecture meeting textbook (Japan Society of Mechanical Engineers), No.930-45 (1993), pp. 51-56.

[4] M.Yoshida, Tribologist (in Japan), Vol.40, No.12 (1995), pp. 998-1002.

[5] T.Murase et al., Journal of the magnetics society of Japan, Vol.19, No.2 (1995), pp. 413-416. 